\title{
Choline kinase-alpha by regulating cell aggressiveness and drug sensitivity is a potential druggable target for ovarian cancer
}

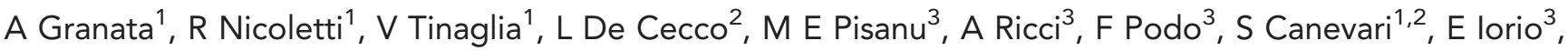 \\ M Bagnoli ${ }^{*, 1,4}$ and D Mezzanzanica*,1,4 \\ ${ }^{1}$ Unit of Molecular Therapies, Department of Experimental Oncology and Molecular Medicine, Fondazione IRCCS Istituto \\ Nazionale dei Tumori, Via Amadeo 42, 20133 Milan, Italy; ${ }^{2}$ Unit of Functional Genomics, Department of Experimental Oncology \\ and Molecular Medicine, Fondazione IRCCS Istituto Nazionale dei Tumori, Via Amadeo 42, 20133 Milan, Italy and ${ }^{3}$ Department of \\ Cell Biology and Neurosciences, Istituto Superiore di Sanità, Viale Regina Elena 299, 00161 Rome, Italy
}

Background: Aberrant choline metabolism has been proposed as a novel cancer hallmark. We recently showed that epithelial ovarian cancer (EOC) possesses an altered MRS-choline profile, characterised by increased phosphocholine (PCho) content to which mainly contribute over-expression and activation of choline kinase-alpha (ChoK-alpha).

Methods: To assess its biological relevance, ChoK-alpha expression was downmodulated by transient RNA interference in EOC in vitro models. Gene expression profiling by microarray analysis and functional analysis was performed to identify the pathway/ functions perturbed in ChoK-alpha-silenced cells, then validated by in vitro experiments.

Results: In silenced cells, compared with control, we observed: (I) a significant reduction of both CHKA transcript and ChoK-alpha protein expression; (II) a dramatic, proportional drop in PCho content ranging from 60 to $71 \%$, as revealed by ${ }^{1} \mathrm{H}$-magnetic spectroscopy analysis; (III) a 35-36\% of cell growth inhibition, with no evidences of apoptosis or modification of the main cellular survival signalling pathways; (IV) 476 differentially expressed genes, including genes related to lipid metabolism. Ingenuity pathway analysis identified cellular functions related to cell death and cellular proliferation and movement as the most perturbed. Accordingly, CHKA-silenced cells displayed a significant delay in wound repair, a reduced migration and invasion capability were also observed. Furthermore, although CHKA silencing did not directly induce cell death, a significant increase of sensitivity to platinum, paclitaxel and doxorubicin was observed even in a drug-resistant context.

Conclusion: We showed for the first time in EOC that CHKA downregulation significantly decreased the aggressive EOC cell behaviour also affecting cells' sensitivity to drug treatment. These observations open the way to further analysis for ChoK-alpha validation as a new EOC therapeutic target to be used alone or in combination with conventional drugs.

Altered metabolism has been recently linked to cancer development, progression and poor clinical outcome (Hanahan and Weinberg, 2011; Ward and Thompson, 2012). In the past years, the introduction of magnetic resonance spectroscopy (MRS) for tumour studies, helped to recognise activated phosphatidyl choline (PtdCho) metabolism as one emerging metabolic hallmark associated with oncogenesis and tumour progression (Podo, 1999; Podo et al, 2011).

Altered choline (Cho) metabolism is characterised by increase in total choline-(tCho) containing metabolites levels essentially due to intracellular pooling of phosphocholine (PCho) that is both a precursor and a breakdown product of PtdCho, one of the major

\footnotetext{
*Correspondence: Dr M Bagnoli; E-mail: marina.bagnoli@istitutotumori.mi.it or Dr D Mezzanzanica; E-mail: delia.mezzanzanica@istitutotumori.mi.it ${ }^{4}$ These authors contributed equally to this work.
} 
components of cellular membranes, required for structural stability and cell proliferation (Podo, 1999; Vance and Vance, 2004; Podo et al, 2011). Among the multiple enzymes involved in both the biosynthetic and catabolic pathways leading to PtdCho synthesis (Ishidate, 1997), evidences grew to support choline kinase (ChoK) as also being rate limiting and regulatory in some circumstances, in particular in transformed cells (Aoyama et al, 2004). Choline kinas catalyses the phosphorylation of free Cho to PCho, and, in mammalian cells, only the alpha-isoform (synthesised by CHKA gene) has a central role in sustaining PtdCho biosynthesis, indeed ChoK-beta alone cannot compensate this activity (Wu et al, 2008). Choline kinase is an interesting enzyme at the crossroads of the main growth factortriggered survival signalling pathways (Ras activation, PI3K signalling) and constitutively activated in some human tumour cells and tissues (see (Glunde et al, 2011a)). Furthermore, a large body of work in cancer cells suggests that ChoK-alpha expression and activity are directly associated not only with increased cancer cell proliferation but also with malignancy, making it a potential prognostic marker of some cancers, such as non-small-cell lung cancer (Ramirez et al, 2007) as well as a potential novel target for image-guided cancer therapy (Glunde et al, 2011b). Addiction of cancer cell survival to metabolic changes opened new therapeutic windows suggesting the possibility of targeting specific metabolic alterations (Vander Heiden, 2011). The cholinic phenotype, characterised by increased ChoK-alpha activity and expression, renders this enzyme an attractive new therapeutic target. The feasibility of ChoK-alpha inhibition as antitumoural therapy is being pursued through the development of chemical inhibitors of its enzymatic activity (Hernandez-Alcoceba et al, 1999; Rodriguez-Gonzalez et al, 2003; Clem et al, 2011) and by silencing CHKA expression by RNA interference (Glunde et al, 2005; Krishnamachary et al, 2009).

Epithelial ovarian cancer (EOC) remains one of the most challenging areas of cancer research. In spite of progress in diagnosis and treatment, EOC incidence and mortality rates have remained unchanged over the last 30 years, mainly because of late diagnosis and disease recurrence with development of chemoresistance (Vaughan et al, 2011), with a resulting 5-year overall survival around 30\% (Siegel et al, 2013). Considering the great molecular heterogeneity of the disease (Kurman and Shih, 2010), and, in the attempt to design and develop more sensitive diagnostic tools as well as novel treatment approaches, a deeper understanding of critical molecules and pathways specifically involved in EOC tumourigenesis and progression is needed (Konstantinopoulos et al, 2008; Chon and Lancaster, 2011; Vaughan et al, 2011). We previously reported that alteration of the tCho MRS profile, with a characteristic increase in the content of intracellular PCho, is a common feature during the progression from non-tumoural or immortalised ovarian cells to EOC cells (Iorio et al, 2005, 2013). By a combined biochemical, functional and genomic approach, we recently showed that these alterations are sustained by activation of enzymes involved in PtdCho biosynthetic as well as catabolic pathways: ChoK-alpha and PtdCho-specific phospholipase C (PtdCho-plc) (Spadaro et al, 2008; Iorio et al, 2010) strongly suggesting a main role for ChoK-alpha in sustaining the PCho increase in EOC cells as well as in EOC growth and progression.

Aiming to assess the biological relevance of Chok-alpha expression and activity in EOC cells, here we specifically silenced CHKA gene expression by transient RNA interference in two EOC cell lines and evaluated the main biological effects related to alterations of tCho-metabolic profiles, global gene expression as well as general cancer cell behaviour.

\section{MATERIALS AND METHODS}

Cell lines. INTOV11 (obtained in our laboratory from a serous high-grade EOC) and SKOV3 (from ATCC) cell lines were maintained in RPMI 1640 (Sigma, St Louis, MO, USA) supplemented with $10 \%(\mathrm{v} / \mathrm{v})$ FCS and $2 \mathrm{mmoll}^{-1}$ L-glutamine (Sigma). Normal ovary cell lines (I64-hTERT) immortalised with hTERT obtained as described (Iorio et al, 2005) were maintained in 199-MCDB105 medium (Sigma) supplemented with 10\% FCS, $2 \mathrm{mmoll}^{-1}$-glutamine, $200 \mu \mathrm{g} \mathrm{ml}^{-1} \mathrm{G} 418$. Cells were maintained at $37^{\circ} \mathrm{C}$ in a humidified incubator under $5 \% \mathrm{CO}_{2}$. Cells were genotyped at the fragment analysis facility of our Institute, using Stem Elite ID System (Promega, Madison, WI, USA), according to manufactures instructions and ATCC guidelines. Cells were routinely confirmed to be mycoplasma-free using the Hoechst staining and MycoAlert Mycoplasma Detection Kit (Lonza, Walkersville, MD, USA).

Transient ChoK silencing. A total of 180000 cells per well were seeded on six-well plates and transfected with a final concentration of $40 \mathrm{~nm}$ specific small interfering RNA (siRNA) against CHKA, NM_212469 and NM_001277 (siGENOME Smart Pool, Thermo Scientific, Dharmacon Inc., Chicago, IL, USA), whereas a nontargeting siRNA was used as control (siGENOME non-targeting siRNA no. 2, Dharmacon). Transfection was carried out using Lipofectamine2000 (Invitrogen, Life Technologies, Carlsbad, CA, USA), according to the manufacturers' protocol. The efficacy of CHKA silencing as well as its related biological effects were assessed at day $3(72 \mathrm{~h})$ after $7 \mathrm{~h}$ transfection, unless otherwise specified.

FlexiTube Gene Solution (Qiagen, Hilden, Germany) siRNA pool targeting CHKA (NM_001277), together with their relative negative controls siRNA (Qiagen), were used in the experiments aimed to exclude off-target non-specific effects, applying the same transfection protocols and siRNA concentration.

Nuclear magnetic resonance spectroscopy. Cells grown to $60-70 \%$ confluence were trypsinised $24 \mathrm{~h}$ after culture medium change, counted and assessed for cell viability (80-90\%) and membrane integrity by trypan blue staining. Cell aqueous extracts (from 5 to $10 \times 10^{6}$ cells per sample) were prepared in $\mathrm{EtOH} 70 \%$ according to an established protocol (Iorio et al, 2010). Briefly, after ultrasonication at $20 \mathrm{kHz}$, supernatants were lyophilised twice and the residue resuspended in $0.7 \mathrm{ml} \mathrm{D}_{2} \mathrm{O}$ (Sigma-Aldrich) containing $0.1 \mathrm{~mm}$ 3-(trimethylsilyl)-propionic-2,2,3,3-d4 acid sodium salt as internal chemical shift and peak area standard. High-resolution NMR experiments $\left(25^{\circ} \mathrm{C}\right.$ ) were performed at $9.4 \mathrm{~T}$ (Bruker AVANCE spectrometer, Karlsruhe, Germany). Proton nuclear magnetic resonance spectroscopy spectra of cell extracts were acquired using $90^{\circ}$ flip angle, $30 \mathrm{~s}$ repetition time, $32 \mathrm{~K}$ time domain data points and 128 transients (Iorio et al, 2005).

Western blotting. Western blot analysis was performed as previously described (Iorio et al, 2010) by separating proteins $(30 \mu \mathrm{g})$ on a $4-12 \%$ SDS-PAGE gel (Invitrogen, Life Technologies). For primary antibodies used see Supplementary Materials. Blots were acquired with a Bio-Rad apparatus using ChemiDoc XRS (Bio-Rad Laboratories Srl) and analysed using Quantity One software (Bio-Rad, Hercules, CA, USA). For densitometric analysis, protein levels were normalised to $\beta$-actin. Relative percentage of expression reported is expressed respective to control oligo-treated cells, set to $100 \%$.

Quantitative Real-Time PCR. Total RNA was extracted from EOC cell lines using the RNA Spin Mini Isolation Kit (GE Healthcare Europe $\mathrm{GmbH}$ ) following the manufacturer's protocol. Complementary DNA was generated from $2 \mu \mathrm{g}$ of RNA using High-Capacity cDNA Archive Kit (Applied Biosystems-Life Technologies, Carlsbad, CA, USA), and RT-qPCR was carried out in triplicate using the 7900 HT FAST Real-Time PCR System (Applied Biosystems-Life Technologies). Specific probes are indicated in Supplementary Materials. The $\Delta \Delta \mathrm{CT}$ method was used to determine the quantity of the target sequences. In all 
RT-qPCR experiments, GAPDH was amplified as endogenous control and I64-hTERT cells were used as calibrator. Analyses were performed using SDS software 2.2.2 (Applied Biosystems-Life Technologies).

Proliferation and drug treatment assays. Cells were seeded in triplicates at $1 \times 10^{5}$ per well on 12 -well plates. After transfection, proliferation was assessed at each time point by Trypan Blue exclusion assay using Countess automated cell counter (Invitrogen, Life Technologies). Cell viability was evaluated as percentage of alive cells in the total cell population. For cytotoxicity assays, the day after transfection 5000 cells per well were seeded in 96-well flat-bottom plates and exposed for $7 \mathrm{~h}$ to cisplatinum (DDP) (TEVA Italia s.r.l, Milan, Italy) at serial dilution starting from $1 \times 10^{-4}$ to $3 \times 10^{-7} \mathrm{M}$, or doxorubicin hydrochloride (Pfizer Italia s.r.l, Rome, Italy) at serial dilution starting from $1 \times 10^{-4}$ to $1 \times 10^{-7} \mathrm{M}$, and for $48 \mathrm{~h}$ to Paclitaxel (Sigma) at serial dilution starting from 2.5 to $0.016 \mathrm{~nm}$. The effects of DDP treatment on cell proliferation were assessed $48 \mathrm{~h}$ later by Sulforhodamine B (SRB) assay as described (Bagnoli et al, 2011). Optical density was measured at $550 \mathrm{~nm}$ in a microplate reader (Bio-Rad model 550). The effects of Doxorubicin (assessed $48 \mathrm{~h}$ after drug treatment) and Paclitaxel were measured using a CellTiter-GLO luminescent cell viability assay performed according to the manufacturer's instructions (Promega).

Cell cycle analysis. Seventy-two hours post transfection, cells were pulsed with $10 \mu \mathrm{M} 5^{\prime}$-bromo-2'-deoxyuridine (BrdU) for $1 \mathrm{~h}$ at $37^{\circ} \mathrm{C}$, collected and serially washed in PBS. Following fixing with $70 \%$ ethanol, cells were processed using BrdU Labelling and detection kit (Roche Diagnostic Corp. Indianapolis, IN, USA) according to manufacturer's protocol. Samples were double-stained by incubation with $5 \mu \mathrm{g} \mathrm{ml}^{-1}$ propidium iodide (Sigma) and $0.5 \mathrm{mg} \mathrm{ml}^{-1}$ RNAse (Sigma) for $30 \mathrm{~min}$ at $4{ }^{\circ} \mathrm{C}$ in the dark, then they were analysed with FACSCanto (Becton-Dickinson, Franklin Lakes, NJ, USA) and the data were processed using FlowJo 7.6.4 Analysis Software (Becton-Dickinson).

Gene expression and Bioinformatic analysis. Total RNA was isolated as described from triplicate cultures of CHKA-silenced and control cells of both EOC cellular models. Five hundred nanograms of quality-checked (Agilent BioAnalyzer, Agilent Technologies Italia, SpA, Milan, Italy) RNA were analysed for global gene expression profiling using HumanHT12_v3 BeadChips (Illumina Inc., San Diego, CA, USA) microarrays and the Illumina BeadArray Reader. Data were collected and analysed using the supplied scanner software and the BeadStudio Version 3 software package. Following hybridisation quality check, the data set was normalised using quantile algorithm. The expression profiles of the 12 samples have been deposited in NCBI's Gene Expression Omnibus (GEO) with GSE accession number GSE39943.

We used BRB Array Tool (v4.2.1; http: //linus.nci.nih.gov/BRBArrayTools.html) to identify the 18308 genes that crossed the threshold of detection $P$-value $\leqslant 0.05$ among all the samples and to derive by class comparison analysis (silenced $v s$ control cells) the list of 476 differentially expressed genes with $P$-value $<0.01$ and FDR $<0.25$. For genes identified by multiple probesets, the probeset with the best-performing FDR was selected.

A data set consisting of the 476 differentially expressed genes was imported into the Ingenuity Pathway Analysis Tool (IPA Tool; IngenuitySystems, Redwood City, CA, USA; http://www.ingenuity. com) based on the Ingenuity Pathway Knowledge Base, derived from known and published genes interactions and functions. Differentially expressed genes are mapped into genetic networks that are ranked according to the number of significantly expressed genes they contain (focus molecules).

Bioplex analysis. Triplicate culture supernatants, from both EOC silenced and control cells, were collected $72 \mathrm{~h}$ post transfection by centrifugation at 1500 r.p.m. for $10 \mathrm{~min}$. A multiplex biometric ELISA-based immunoassay, containing dyed microspheres conjugated to monoclonal antibodies specific for IL6 and IL8 was used according to the manufacturer's instructions (Bioplex, Bio-Rad Lab Inc.). Cytokines quantifications, referred to a standard curve, were determined using a Bio-Plex array reader (Luminex, Austin, TX, USA) with software provided by the manufacturer (Bio-Plex Manager Software).

Immunofluorescence microscopy. Cells were fixed in $4 \%(\mathrm{w} / \mathrm{v})$ paraformaldehyde in PBS for 20 min at room temperature, washed twice with PBS and permeabilised for $10 \mathrm{~min}$ at room temperature with $0.1 \%$ Triton X-100 (Sigma) in PBS. After rinsing twice in PBS$0.1 \%$ Tween $(\mathrm{v} / \mathrm{v})$, cells were incubated with Alexa-488 conjugated phalloidin (Invitrogen, Life Technologies) (1:150) in PBS with 1\% BSA for $1 \mathrm{~h}$ to visualise F-actin. After washing twice in PBS- $0.1 \%$ Tween slides were mounted with ProLong Gold antifade reagent with DAPI (Invitrogen, Life Technologies) for nuclei staining. Images were acquired using a Nikon Eclipse Te-2000 phasecontrast microscope.

Wound-healing assay. A scratch was made with a micropipette tip across a confluent monolayer of $2.5 \times 10^{5}$ transfected cells, seeded directly in 24-well plates or on glass coverslip when assayed by immunofluorescence. Cells were then incubated in serum-free culture medium after removing floating cells. Wound healing was visualised by comparing photographs taken at the time of scratch and 24, 48 and $72 \mathrm{~h}$ later, by a Nikon Eclipse Te-2000 inverted microscope. The distance travelled by the cells was the wound width at each times of observation subtracted from the wound width at time 0 . The values obtained were then expressed as percentage of migration, setting the gap width at t0 as $100 \%$. The assay was also performed in presence of Actinomycin D (Sigma) at $2 \mathrm{ng} \mathrm{ml}^{-1}$ concentration that we observe to inhibit cell proliferation without inducing cell death.

Migration assay. To account for methodological variability, migration assays were performed using two assays both based on the Boyden chamber principle but having different detection methods: 24-well Transwell chamber system (Costar Corning Inc., Corning, NY, USA) and 24-Well Fluorimetric Cell Migration Assay (Merck Millipore, Billerica, MA, USA).

For the first assay, $1.5 \times 10^{5}$ transfected cells were seeded in the upper chamber in $0.3 \mathrm{ml}$ serum-free culture media. Media supplemented with $10 \%$ fetal bovine serum was placed in the bottom well in a volume of $0.7 \mathrm{ml}$ (used as a chemoattractant). After incubation for $24 \mathrm{~h}$ at $37^{\circ} \mathrm{C}$ in an atmosphere containing $5 \%$ $\mathrm{CO} 2$, migrated cells on the lower surface were stained with SRB. Migration was quantified using Odyssey Infrared laser scanner (Li-Cor Biosciences, Lincoln, NE, USA) at Infrared wavelength of $700 \mathrm{~nm}$, after removing the noninvading cells on the upper side of the membrane with cotton swabs. For fluorimetric assay, transfected cells were seeded in the upper chamber at $5 \times 10^{5}$ cells $/ \mathrm{ml}$ in $0.3 \mathrm{ml}$ serum-free culture media. Media supplemented with $10 \%$ fetal bovine serum was placed in the bottom well in a volume of $0.5 \mathrm{ml}$ (used as a chemoattractant). After incubation for $24 \mathrm{~h}$ at $37^{\circ} \mathrm{C}$ in an atmosphere containing 5\% CO2, assay was performed according to the manufacturer's instructions (Merck Millipore). The migrating cells were determined by fluorescence and reported as relative fluorescence units (RFUs). The assay was also carried out by adding $2 \mathrm{ng} \mathrm{ml}^{-1}$ of Actinomycin D (Sigma).

Cell invasion Assay. Cell invasion was tested using a BD BioCoat Matrigel Invasion Chamber (Cat no. 354480 Becton-Dickinson). The inserts were transferred into the wells containing serum-free medium. Then, cells were harvested $72 \mathrm{~h}$ after transfection and resuspended in fresh medium were added at a density of $5 \times 10^{4}$ cells per well. Cell invasion into the Matrigel was determined after $22 \mathrm{~h}$ of culture at $37^{\circ} \mathrm{C}$. The membrane with invading cells was 
fixed with absolute methanol and stained with $1 \%$ crystal violet in methanol. Invasion was quantified using Odyssey Infrared laser scanner (Li-Cor Biosciences) at Infrared wavelength of $700 \mathrm{~nm}$, after removing the noninvading cells on the upper side of the membrane with cotton swabs.

Statistical analysis. Data were analysed using Prism GraphPad Software Version 5. Statistical significance of differences was determined by one-way ANOVA or by Student's $t$-test, as specified. Differences were considered significant at $P<0.05$. Asterisks in all figures denote a statistically significant difference in comparison with the relative control ${ }^{\star} P<0.05$; ${ }^{\star *} P<0.01$; ${ }^{* *} P<0.001$. Data reported are the mean \pm s.d. of at least three independent experiments unless otherwise indicated.

\section{RESULTS}

Transient CHKA silencing drastically reduces ChoK-alpha expression and activity. Choline kinase-alpha expression was inhibited by specific transient RNA interference in two EOC cell lines, INTOV11 and SKOV3, with known ChoK-alpha expression and overactivation (see (Iorio et al, 2005, 2010) for SKOV3 and Supplementary Figure 1 for INTOV11). Silencing efficacy was evaluated $72 \mathrm{~h}$ after transfection both at transcript and protein level. We obtained a significant reduction of $68 \pm 12 \%$ and $75 \pm 10.7 \%$ of CHKA mRNA transcript in siCHKA-INTOV11 and siCHKA-SKOV3, respectively, as compared with their relative control (Figure 1A). A drastic inhibitory effect of siCHKA was observed also at the protein level (Figure 1A lower panel), where the densitometric analysis showed a consistent and significant protein downmodulation of $83 \pm 11 \%$ and $80 \pm 3.5 \%$ on INTOV11 and SKOV3 cell lines, respectively $(P<0.01)$. To confirm the specificity of our siRNA pool as regard to the ChoK isoform silenced, we analysed the ChoK-beta isoform mRNA expression levels in the CHKA-silenced cells. In both $C H K A$-silenced EOC cell lines, levels of $C H K B$ transcript remained unchanged as compared with the control (Figure 1B).
Proton magnetic resonance spectroscopy spectra on cellular ethanolic extracts revealed in both siCHKA-cell lines an overall reduction of PCho content as a consequence of CHKA silencing in all the performed experiments (two representative examples are in Figure 1C). The protein downmodulation (inset of Figure 1C, lower panel), as an indirect measure of ChoK-alpha activity, reflected the decrease in PCho content as shown in expanded regions of the corresponding ${ }^{1} \mathrm{H}$-MRS spectra profiles. Despite the biological variability and the spread due to deconvolution analyses, we observed consistent decreases of $60.4 \pm 9.7$ and $70.8 \pm 10.9 \%$ in the PCho content of silenced INTOV11 and SKOV3 cells, respectively. Accordingly, the overall tCho contents also decreased $(41.4 \pm 21.4 \%$ and $44 \pm 26.5 \%$ in silenced INTOV 11 and SKOV3 cells, respectively). Glycerophosphocholine absolute concentration, although highly variable, was not significantly changed by $C H K A$ knockdown being $3.7 \pm 4.0 \mathrm{nmol}$ per $10^{6}$ cells in silenced SKOV3 cells compared with $0.8 \pm 0.6 \mathrm{nmol}$ per $10^{6}$ cells in the corresponding controls. The slight (if any) increase of GPC in silenced cells is in agreement with a similar observation previously reported for ChoK-alpha depleted MD-MBA-231 breast cancer cells (Glunde et al, 2005) and it could be due to lipases' activation, associated with neutral lipid accumulation particularly seen in breast and ovary carcinoma. No changes were observed in GPC in CHKAsilenced INTOV11 cells compared with their controls $(1.8 \pm 2.2 v s$ $1.8 \pm 1.4 \mathrm{nmol}$ per $10^{6}$ cells). Similar results were obtained for free choline, whose mean levels were maintained at $2 \pm 1 \mathrm{nmol}$ per $10^{6}$ cells in all experiments.

Choline kinase-alpha downregulation inhibits cell proliferation without affecting survival signalling pathways. Kinetics of cell proliferation after transfection showed a cell growth inhibition in siCHKA cells already detectable at $24 \mathrm{~h}$ and with a significant $35 \%$ reduction at $72 \mathrm{~h}$ in both models (Figure $2 \mathrm{~A}$ ). No relevant changes in cell viability were observed between siCHKA and control cells, being $>95 \%$ cells viable in all analysed models, whereas, a $35-38 \%$ reduction in the $\mathrm{S}$-phase $\mathrm{BrdU}$ incorporation, proportional to growth inhibition, was determined in both siCHKA cells. A representative experiment is shown in Figure 2B. Analysis of
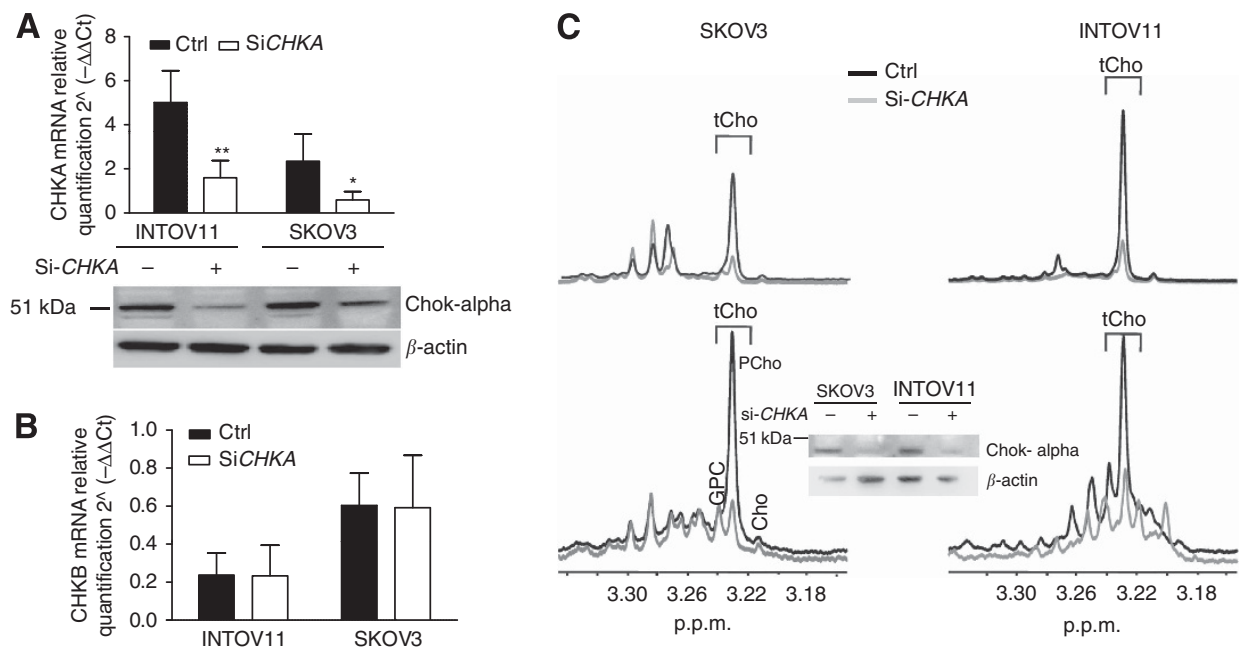

Figure1. Transient CHKA silencing efficiently downmodulates ChoK-alpha and intracellular PCho content in EOC cell lines. (A): CHKA silencing was confirmed at mRNA (RT-qPCR, upper panel; data are the mean \pm s.d. of five independent experiments) and protein expression level (lower panel: western blotting of a representative experiment is reported). (B): RT-qPCR for ChoK $\beta$-isoform. Data are the mean \pm s.d. of five independent experiments. GAPDH was amplified as endogenous control and I64-hTERT cells preparations were used as calibrator. (C): Representative examples of alterations induced by siCHKA on the ${ }^{1} \mathrm{H}-\mathrm{MRS}$ tCho profile and its PCho component. Black lines: control cells; grey lines: silenced cells. Inset in lower panel: western blot of control and siCHKA EOC cells probed with specific antibody to ChoK-alpha. GPC, glycerophosphocholine; PCho, phosphocholine; tCho, total choline-containing compounds. The PCho/tCho ratio was $0.75 \pm 0.20$ in both cell types before silencing. 

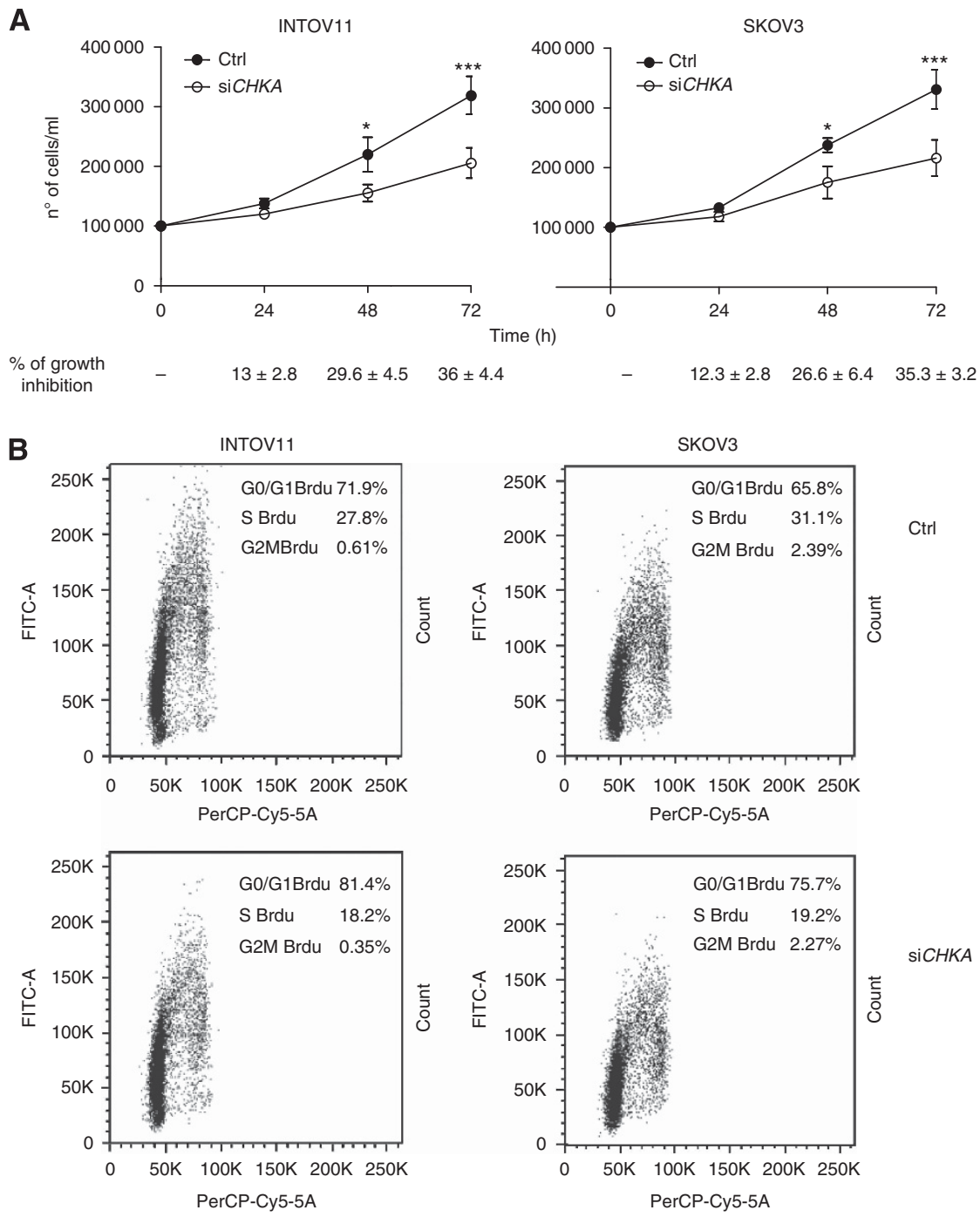

Figure 2. Cell proliferation upon CHKA silencing. (A): Proliferation curves. Viable cells were counted 24, 48 and $72 \mathrm{~h}$ post-transfection. Mean percentage of growth inhibition of CHKA-silenced vs control cells is reported below. (B): Representative experiment of BrdU incorporation at $72 \mathrm{~h}$ after transfection.

cell cycle also showed a slight G1 cell-cycle arrest in silenced cells compared with controls ( $12 \pm 4 \%$ in both models). Cells with hypodiploid DNA content, suggestive of activation of apoptotic signalling, were not observed (data not shown).

To assess the specific biological impact in EOC cells lines, CHKA silencing was performed also on the non-tumoural ovarian cell line I64-hTERT (Iorio et al, 2005). siCHKA transfection in I64hTERT decreased ChoK-alpha expression at both mRNA and protein levels (Supplementary Figure 2A and B) and dropped cellular PCho content (Supplementary Figure 2C). It has to be noted that the basal level of PCho in I64-hTERT is $2.3 \pm 1.3 \mathrm{nmol}$ per $10^{6}$ cells, consistent with our previously published data (Iorio et al, 2005) and significantly lower than that measured in EOC. CHKA silencing induced a consistent decrease in PCho content. However, no significant effects on cell proliferation were observed in the non-tumoural cell line I64-hTERT (Supplementary Figure 2D) in spite of a cell turnover comparable to EOC cells (Figure 2A and Supplementary Figure 2D), thus confirming that ChoK-alpha sustains the cholinic phenotype only in EOC cells.

Given the effects on cell proliferation and the data available in literature for cancer others than ovary (Yalcin et al, 2010; Clem et al, 2011) reporting a positive feed-back signalling loop existing among ChoK-alpha and the main cellular survival signalling pathways, we evaluated the effects of CHKA silencing on AKT and MAPK activation immediately after siRNA transfection and at 24-72 h of relapse. No consistent differences of phosphorylation levels of pAkt (S473) and pMAPK (p44-42) or in total Akt and ERK1/2 protein levels were observed in both CHKA-silenced cells compared with controls (Supplementary Figure 3).

Modulation of gene profiling associated to CHKA silencing. As the biological outcomes observed in siCHKA EOC cell lines were not super imposable to features described in other tumour models, we investigated alteration of global gene expression profile upon CHKA silencing to possibly identify the main pathways affected.

By class comparison analysis of INTOV11- and SKOV3-CHKA silenced $v s$ control cells, we identified 476 differentially expressed genes in CHKA silenced as compared with control cells, 252 of them being downregulated (Supplementary Table 1). Importantly, $C H K B$ gene was not included among the modulated genes thus confirming the data obtained by RT-qPCR (see Figure 1B). Furthermore, none of the genes associated to the biosynthetic Kennedy's Pathway resulted differentially expressed between CHKA-silenced and control cells apart from a weak decrease (0.8-fold change in expression, FDR $=0.21$ and $P=0.0049)$ of the GDPD5 gene, involved in the catabolic pathway leading to Choline 


\begin{tabular}{|c|c|c|c|c|}
\hline Gene symbol & $\begin{array}{c}\text { Parametric } \\
\boldsymbol{P} \text {-value }\end{array}$ & $\mathrm{FDR}^{\mathrm{a}}$ & $\begin{array}{l}\text { Geometric } \\
\text { mean of } \\
\text { intensities }^{b}\end{array}$ & \\
\hline CHKA & $4.60 \mathrm{E}-06$ & 0.0421 & 0.44 & $\begin{array}{l}\text { Downregulated } \\
\text { genes }\end{array}$ \\
\hline CCNA1 & $2.60 \mathrm{E}-06$ & 0.0421 & 0.48 & \\
\hline KRT80 & 0.0005081 & 0.128 & 0.51 & \\
\hline IL6 & 0.0046555 & 0.213 & 0.51 & \\
\hline TAGLN & 0.0064673 & 0.236 & 0.53 & \\
\hline IL8 & $9.30 \mathrm{E}-06$ & 0.0467 & 0.54 & \\
\hline AKAP12 & 0.0009146 & 0.145 & 0.56 & \\
\hline $\mathrm{H} 19$ & $3.29 \mathrm{E}-05$ & 0.106 & 0.59 & \\
\hline IDH2 & $5.34 \mathrm{E}-05$ & 0.106 & 0.59 & \\
\hline TNFRSF25 & 0.0011795 & 0.148 & 0.61 & \\
\hline KRT7 & 0.0016046 & 0.163 & 0.61 & \\
\hline LIMK1 & 0.0054187 & 0.222 & 0.61 & \\
\hline MAD2L1 & $8.14 \mathrm{E}-05$ & 0.124 & 0.62 & \\
\hline SEC23A & 0.0001111 & 0.124 & 0.62 & \\
\hline SNX25 & 0.0007806 & 0.137 & 0.62 & \\
\hline ARFIP1 & 0.0009437 & 0.146 & 1.57 & $\begin{array}{l}\text { Upregulated } \\
\text { genes }\end{array}$ \\
\hline CA5B & 0.0022191 & 0.169 & 1.57 & \\
\hline LAMC1 & 0.0002072 & 0.124 & 1.59 & \\
\hline C5 & 0.0013041 & 0.155 & 1.6 & \\
\hline PRSS35 & 0.0004709 & 0.128 & 1.62 & \\
\hline SPTLC3 & 0.0002098 & 0.124 & 1.63 & \\
\hline UBE2E3 & 4.63E-05 & 0.106 & 1.64 & \\
\hline BCMO1 & 0.0001368 & 0.124 & 1.64 & \\
\hline ID3 & 0.0032983 & 0.19 & 1.67 & \\
\hline PPAP2A & 0.0001578 & 0.124 & 1.71 & \\
\hline LRRC31 & 0.0001612 & 0.124 & 1.72 & \\
\hline RTN4 & 3.78E-05 & 0.106 & 1.76 & \\
\hline FXYD2 & 0.0025975 & 0.175 & 1.84 & \\
\hline TNFRSF11B & 0.0001958 & 0.124 & 1.85 & \\
\hline ACSM3 & $4.54 \mathrm{E}-05$ & 0.106 & 2.11 & \\
\hline \multicolumn{5}{|c|}{ 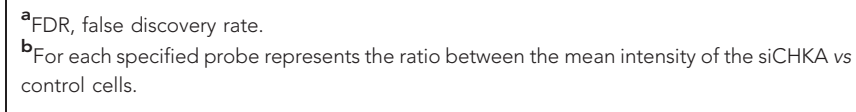 } \\
\hline
\end{tabular}

formation (Supplementary Table 1). The 15 genes most consistently up or downregulated following CHKA silencing are reported in Table 1. Among the most relevant co-repressed genes, we focused our attention on Cyclin A1 (CCNA1), related to regulation of cell cycle progression and cytokines genes (IL6 and IL8) related to inflammation and EOC aggressiveness. Among the most upregulated genes, we identified as gene of interest Acyl-CoA synthetase (ASCM3) needed for fatty acid synthesis, phosphatidic acid phosphatase 2A (PPAP2A), a member of the phosphatidic acid phosphatase (PAP) family and osteoprotegerin (TNFRSF11B; OPG), a soluble decoy receptor for receptor activator of nuclear factor-kappa B ligand (RANKL).

Microarray data showing differential expression of selected genes were biologically validated by three independent silencing experiments for each cell line. ASCM3 and PPAP2A were confirmed to be upmodulated in both CHKA-silenced cell lines by RT-qPCR. Osteoprotegerin instead was significantly upregulated only in INTOV11 CHKA-silenced cells, whereas only a trend was observed in the SKOV3 model $(P=0.07)$ (Figure $3 \mathrm{~A})$. Considering the co-repressed genes, significant downregulation of CCNA1 was confirmed in both SKOV3- and INTOV11silenced cells (Figure 3B). Cyclin A1 downmodulation was evident also at the protein level with a $25 \%$ and $77 \%$ reduction in SKOV3 and INTOV11 cells, respectively (Supplementary Figure 4). Downmodulation of IL6 resulted statistically significant only in INTOV11-silenced cell line. On the contrary, downmodulation of IL8 was statistically significant only in SKOV3 with only a trend for the INTOV11 model $(P=0.08)$. Evaluation of IL6 and IL8 cytokine content in the conditioned medium of transfected cells showed a decrease in the release generally proportional to the efficacy of CHKA silencing. The modulation was more consistent in INTOV11 CHKA-silenced cells as we observed 86\% reduction for IL6 and 66\% for IL8 release in spite of the low-level of the cytokine production, whereas in the siCHKASKOV3 model, we observed a 70\% of inhibition of IL6 release and only a slight reduction of IL8 release (10\% of decrease). To exclude that these observations could be due to nonspecific off-target effects, CHKA-specific silencing and co-modulation of selected genes were validated by RT-qPCR using a second independent CHKA-specific siRNA pool (Supplementary Figure $5 \mathrm{~A}$ and $5 \mathrm{~B})$.

CHKA silencing modulates cell functions related to cell movement and affects drug sensitivity. To derive the possibly deregulated pathways a data set consisting of the 476 differentially expressed genes was analysed with IPA Tool, revealing 25 significantly altered pathways (the top 10 networks, all with a score greater than 20, are reported in Supplementary Table 2). Significantly, the network identified with the highest score included CHKA among the focus molecules. The biological functions associated to this network were related to cell morphology, cellular assembly and organisation, cellular function and maintenance (See Figure 4 for details).

When exploring the molecular and cellular functions affected by CHKA silencing, the functions named as 'Cell Death', 'Cellular Growth and Proliferation' and 'Cellular Movement' were found as the most significantly perturbed (Supplementary Figure 6A). Interestingly, as shown by the z-score heatmaps (Supplementary Figure 6B), Cellular Movement and Cellular Growth and Proliferation functions were predicted to be decreased, whereas Cell Death function was predicted to be increased in CHKAsilenced cells as compared with their control. Indeed, following CHKA knockdown, a decreased proliferation was evident (see Figure 2B) and, as expected, a clear delay in wound closure was observed in both CHKA-silencing cell lines using the classic scratch assay (Figure 5A). As the significantly reduced cell motility observed in $C H K A$-silenced cells as compared with their control cells could be partially due to a reduced proliferation capacity, to possibly exclude effects of CHKA silencing related to proliferation rather than migration, scratch assay was also performed in the presence of Actinomycin D obtaining comparable inhibitory effects. Indeed, we observed an inhibition of wound repair of $46 \% \pm 5.6$ and $45 \% \pm 5.4$ in INTOV 11 and SKOV3 CHKA-silenced cell line as compared with their relative control and of $37 \% \pm 2.7$ and $37 \% \pm 2.9$ in the presence of Actinomycin D in the same cell lines; thus suggesting that results observed were mostly related to alterations of the migratory rather than proliferative phenotype. In addition, CHKA-silenced cells showed a dramatic rearrangement of F-actin fibres with a significant reduction of oriented actin stress fibres and focal adhesion sites (Figure 5B, red arrows), further suggesting that CHKA-silenced cells are less prone to movement and migration as compared with their control cells. 
A
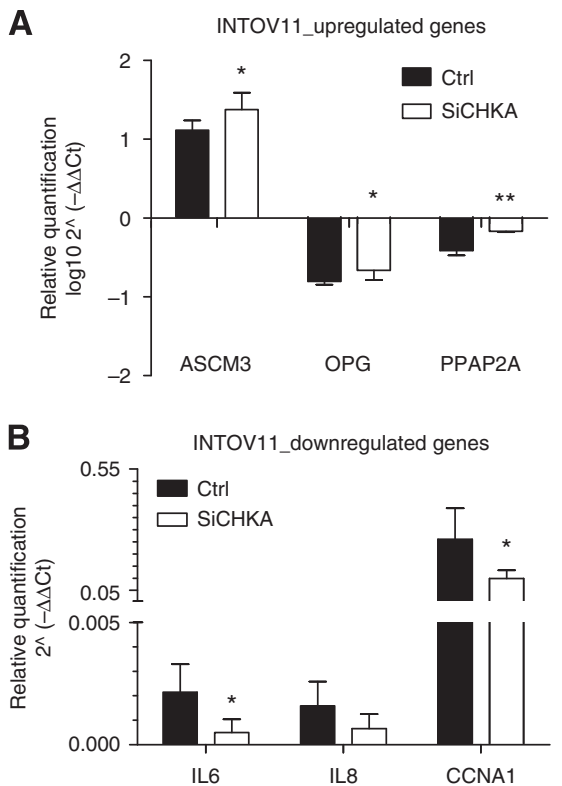

C

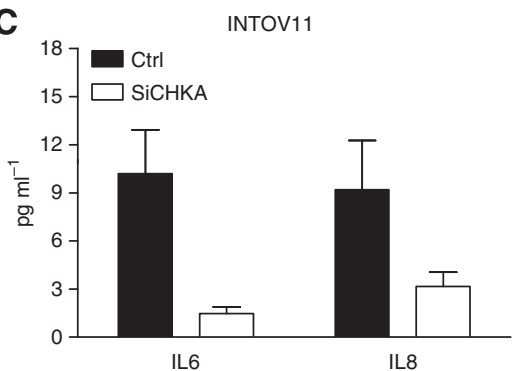

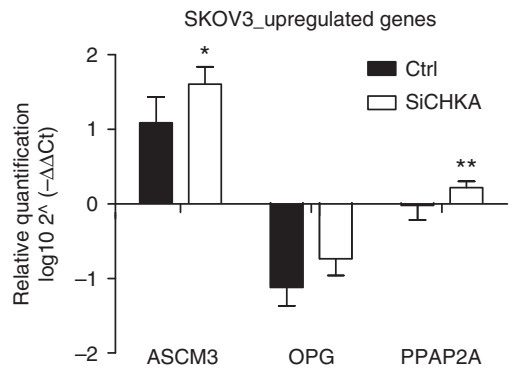
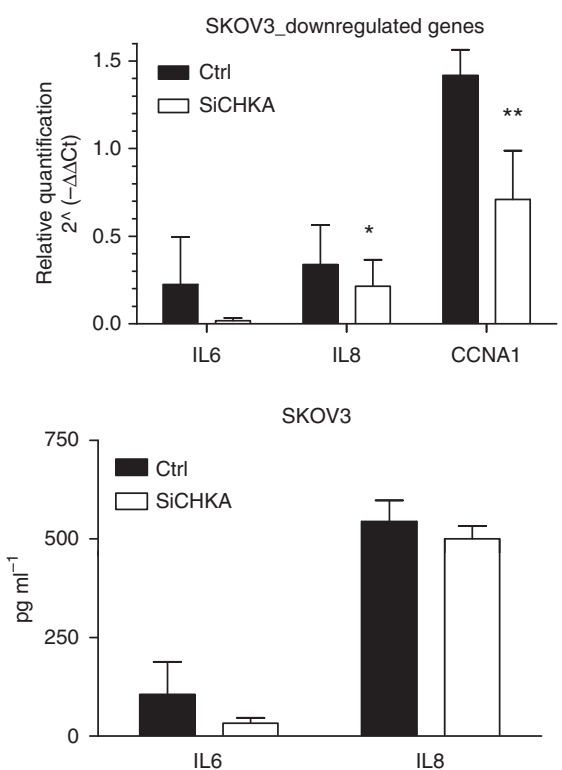

Figure 3. Validation of genes perturbed by CHKA silencing. RT-qPCR of selected up (A) and down (B) modulated genes in CHKA-silenced EOC cell lines. GAPDH was amplified as endogenous control, and I64-hTERT cells preparations were used as calibrator. The mean of five independent experiments is reported. (C) Evaluation of IL6 and IL8 release by bioplex assay on conditioned media from both EOC cell lines. Data are the mean \pm s.d. of three independent experiments.

To confirm these observations, we then assessed migration capability by using two assays both based on the Boyden chamber principle but having different detection methods to account for methodological variability and in presence or absence of Actinomycin D to exclude bias related to proliferative effects. Results obtained (see Figure 6A and B) showed a 43-47\% inhibition of migration in INTOV11 and SKOV3 CHKA-silenced cells as compared with their relative controls when migration was detected by Fluorimetric assay; comparable results were obtained when Actinomycin D was added to culture medium (Figure 6A). In addition, a $37-65 \%$ inhibition of migration was detected in INTOV11 and SKOV3 cells as compared with their relative controls when migration was detected by quantification of SRB staining (Figure $6 \mathrm{~B}$ ).

Furthermore, CHKA-silenced cells showed a significantly reduced $(72 \%$ and $79 \%$ in silenced INTOV11 and SKOV3, respectively) invasive potential through Matrigel as compared with their control cells (Figure 6C).

Our observations on CHKA-silenced cells did not show any direct effect of ChoK downregulation on cell death. However, to possibly confirm the IPA-predicted modulation, we evaluated sensitivity to drug treatments upon CHKA silencing. As compared with their relative untreated cells, we observed a significant increase of sensitivity to DDP treatment associated with CHKA silencing in both INTOV11- and in the DDP-resistant SKOV3 cell lines (Figure 7A). CHKA-silenced cells showed also a significantly increased sensitivity to Doxorubicin and Paclitaxel (Figure 7B and C), two drugs currently used in EOC treatment.

\section{DISCUSSION}

Cancer cells are able to activate signalling pathways that change their metabolism. Aberrant choline metabolism, characterised by an increased intracellular PCho pooling mainly related to increased Chok activity, is a fairly new metabolic hallmark able to discriminate cancer cells having a cholinic phenotype (Glunde et al, 2011a). Our recent works showed an increased expression and over activation of ChoK-alpha in EOC cells that we already characterised for their increased PCho content. Here we show for the first time in EOC that, by using siRNA specific for ChoK-alpha, the expression and the activity of the enzyme can be downmodulated in two models of EOC affecting cell behaviour and sensitivity to drug treatment. The biological effects were evident only in EOC cell lines and not in the non-tumoural ovarian I64hTERT cell line in spite of the comparable cellular turnover of the two cellular models (Iorio et al, 2005 and present results). Our results, in agreement with those by Mori et al (2013) in other type of non-tumoural cells (i.e., endothelial), further support the concept of ChoK-alpha as the major player in supporting cholinic phenotype only in tumour cells (Glunde et al, 2011a). All together these observations strongly suggest a possible reliance of EOC cells survival on the abnormal ChoK-alpha activity and expression (Iorio et al, 2005, 2010; Spadaro et al, 2008; Podo et al, 2011) that if verified, could be successfully exploited for therapeutic purpose. Epithelial ovarian cancer conventional approaches (aggressive debulking surgery followed by platinum-taxane chemotherapy) 


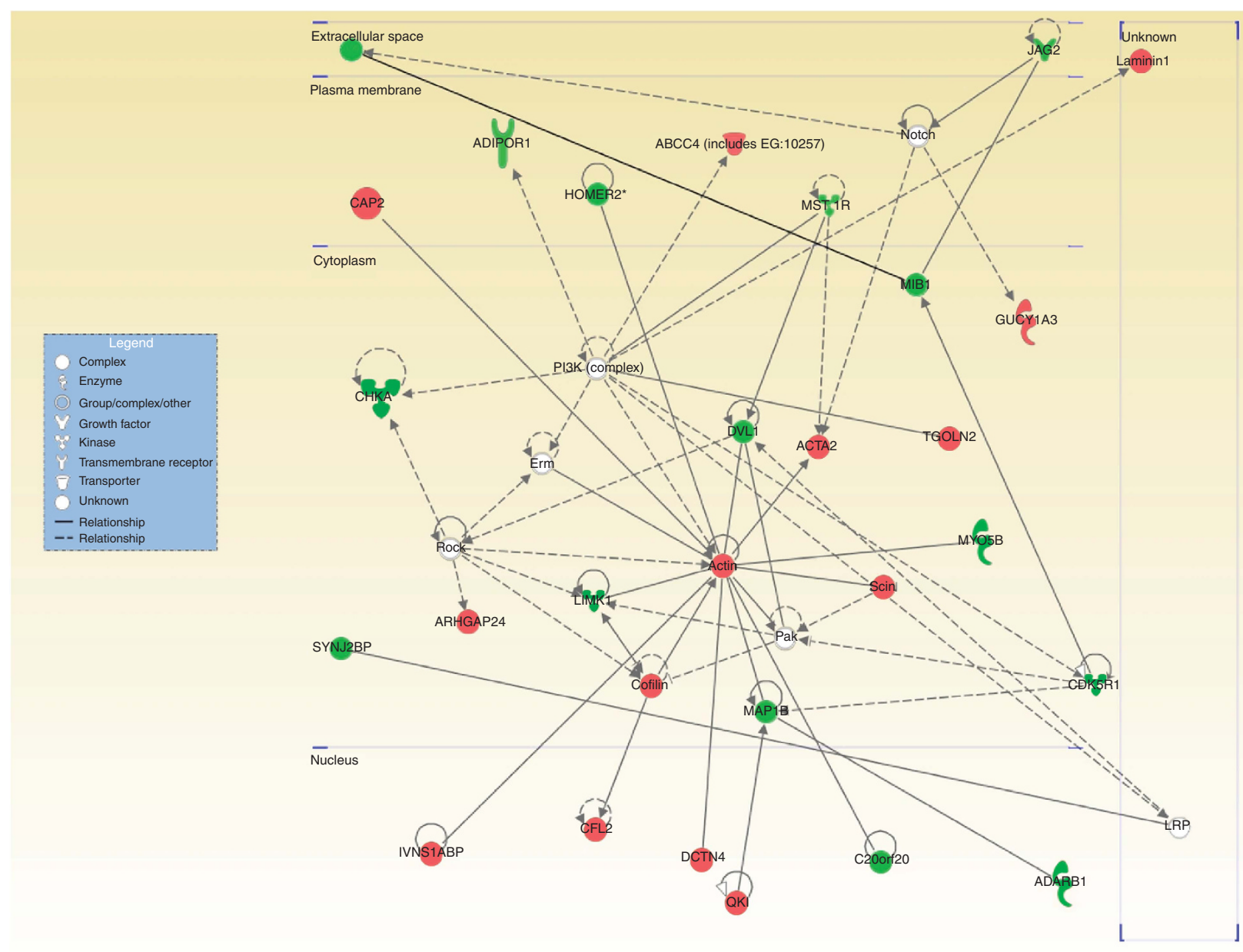

Molecules of the network:

ABCC4, ACTA2, Actin, ADARB1, ADIPOR1, ARHGAP24, C20orf20, CAP2, CDK5R1, CFL2, CHKA, Cofilin, DCTN4, DLL3, DVL1, Erm, GUCY1A3,

HOMER2, IVNS1ABP, JAG2, Laminin1, LIMK1, LRP, MAP1B, MIB1, MST1R, MYO5B, Notch, Pak, PI3K(complex), QKI, Rock, SCIN, SYNJ2BP, TGOLN2

Figure 4. Graphical representation of the most highly rated network as obtained by IPA. The defined statistically significant genes are shaded and the intensity of the shading shows the degree of relative modulation. Red and green shading are for up or downregulated genes in $\mathrm{CHKA}$ silenced cells. A solid line represents a direct interaction between the two gene products and a dotted line means there is an indirect interaction. All molecules participating to the network are listed below. The focus molecules of the network significantly affected by CHKA silencing are reported in red or green colour, depending on their relative modulation as above described.

A INTOV11
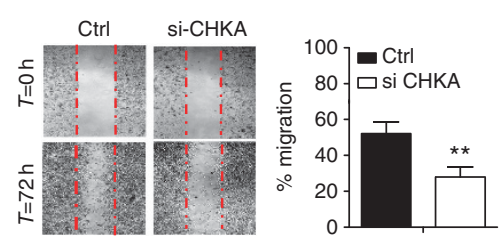

SKOV3

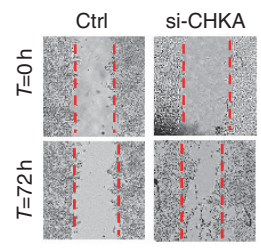

B

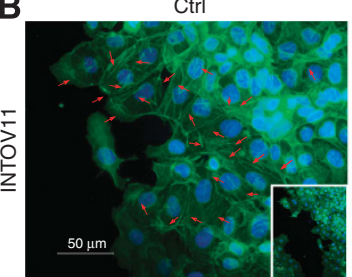

Ctrl

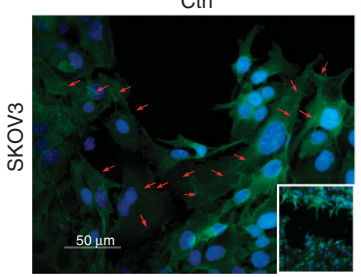

si-CHKA

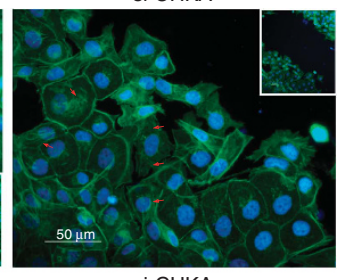

Si-CHKA

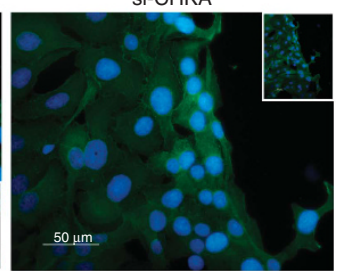

Figure 5. CHKA silencing regulates cell migration and induces alteration in F-actin organisation. (A): Wound-healing assay: photographs of a representative experiment of three performed taken at the time of scratch $(t=0)$ and at $t=72 \mathrm{~h}$. Magnification $\times 200$ : mean percentage \pm s.d. of migration at $t=72 \mathrm{~h}$ is reported in the graph for each cell line. (B): Representative immunofluorescence staining of INTOV11 and SKOV3 CHKAsilenced and control cells. Cells were wounded $72 \mathrm{~h}$ after transfection and analysed $24 \mathrm{~h}$ later. F-actin filaments were visualised as green fluorescence through Alexa-488-phalloidin binding, and cell nuclei were stained by DAPI. Actin stress fibers and focal adhesion sites are indicated by red arrows (Magnification: $\times 300$ ). In each panel, a picture of the wound border is reported in the inset (Magnification $\times 200$ ). 

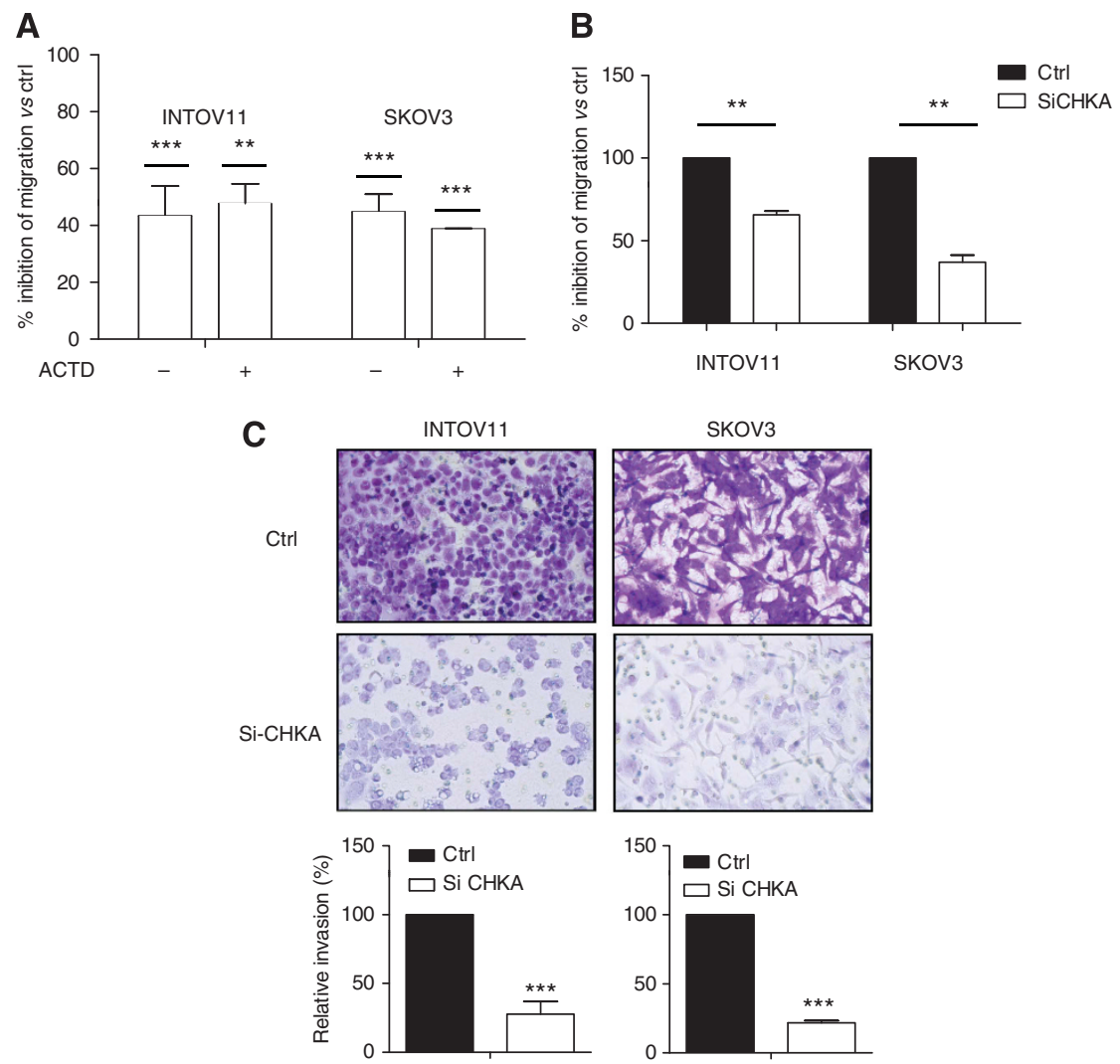

Figure 6. CHKA-silenced cells display reduced motility and invasion. Cells migrating through the membrane were measured by (A). RFU of CyQUANT dye binding to cellular nucleic acids in the lysates or (B). Odyssey infrared laser scanner quantification after SRB staining. In the graphs is reported the percentage of inhibition of migration in CHKA-silenced INTOV11 and SKOV3 cells as compared with their relative controls (oligotreated cells), to which significance is referred. Data are the mean \pm s.d. of three to six independent experiments. (C): upper panels. photographs of a representative experiment of the matrigel-coated membrane invading cells. Magnification $\times 200$. lower panel: mean relative percentage $\pm \mathrm{s}$.d. of invasion capability calculated respect to control oligo-treated cells set to $100 \%$.

(Sandercock et al, 2002) have shown to be largely ineffective in achieving patients' cure (Agarwal and Kaye, 2003), especially due to the occurrence of chemoresistant relapse. Although ChoK-alpha impairment by siRNA might have some limitations when transferred in a clinical context essentially due to the stability of the effect and delivery of siRNA, it, however, represents the most effective way to assess the central role of ChoK-alpha in favoring EOC cell survival and its druggability; thus fostering the development of new chemical drugs with higher specificity and lower systemic toxicity.

The effects related to CHKA transient silencing in EOC appeared to have perturbation on EOC cell behaviour different than that observed in other cellular models. For instance, neither we observed a reduction of Akt phosphorylation in a PI3K-independent way (Chua et al, 2009) nor an attenuation of MAPK and PI3K/AKT signalling (Yalcin et al, 2010). Furthermore, although cell proliferation was reduced in both cell lines after CHKA silencing, neither decrease of cell viability nor apoptosis were observed in silenced cells. In this respect, EOC seems to behave differently than other tumour types in which targeting ChoK by siRNA technology (Banez-Coronel et al, 2008; Gruber et al, 2012) or by pharmacological inhibitors (Rodriguez-Gonzalez et al, 2003, 2005) was able to induce an apoptotic effect. Nevertheless, the efficacy of transient CHKA silencing in our two cellular models in inducing a dramatic drop in PCho content, as observed in siCHKA cells by ${ }^{1} \mathrm{H}$-MRS analysis, especially confirmed the dependence of EOC cholinic phenotype on elevated ChoK-alpha expression and activity. Indeed, apart from CHKA downmodulation, none of the genes associated to the biosynthetic Kennedy's Pathway resulted perturbed after transient CHKA silencing.

However, when gene expression analysis was performed on silenced CHKA cells, perturbations of the most comodulated genes were overall suggestive of a less aggressive phenotype. From a metabolic point of view, comodulatted genes were especially related to fatty acids (such as triacylglycerides (TAG)) synthesis and accumulation of cytoplasmic lipid droplets (ACSM3, (Iorio et al, 2003; Glunde et $a l, 2005)$ ) as well as biolipid mediators ( $P P A P 2 A)$. Interestingly, $P P A P 2 A$ converts phosphatidic acid (PA) that participates in a number of signalling functions to diacylglycerol. It has been reported that an increase in PPAP $2 A$ activity, due to a gene upmodulation, could terminate the Raf-1 and the MAP-kinase pathway signalling overall affecting cell proliferation (Roberts and Morris, 2000). Although we did not observe consistent modulation of these signalling in our experimental setting, we observed a consistent and reproducible decrease of IL6 and IL8 mRNA levels associated to a decrease of protein release in conditioned supernatant of siCHKA cells. It is now established that in EOC IL6 and IL8 expression is induced by lysophosphatidic acid (LPA) (Fang et al, 2004; So et al, 2004; Nilsson et al, 2005) a biolipid that, by upregulating these cytokines, stimulates tumour cell invasion and metastasis. Interestingly, LPA can be produced by breakdown of PA generated by the activity of phospholipase D, an enzyme involved in the catabolic pathway of PtdCho (see (Iorio et al, 2005) and (Aoki et al, 2008)). Downmodulation of these cytokine might be then related to a lower availability of LPA as a consequence of a decreased PtdCho synthesis and subsequent degradation by the catabolic pathway. 

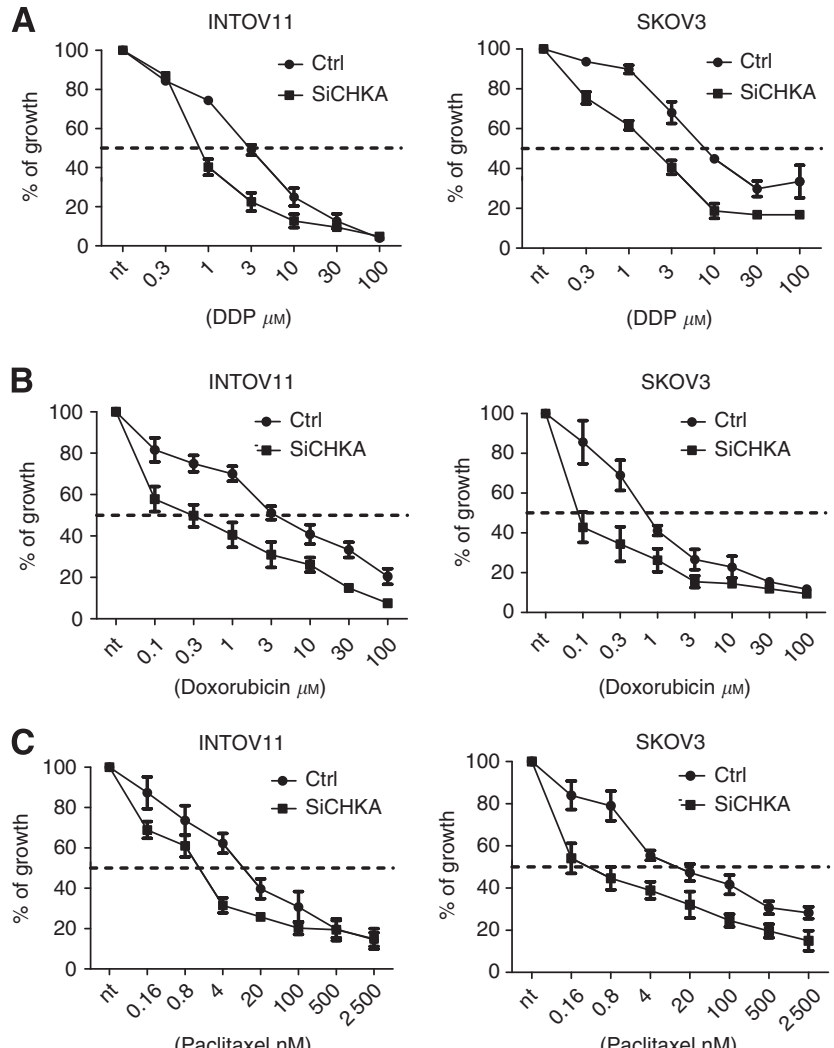

Figure 7. CHKA silencing induce sensitivity to drug treatment. Cytotoxicity assay: Sensitivity to: (A) cisplatinum (DDP, from $1 \times 10^{-4}$ to $3 \times 10^{-7} \mathrm{M}$ ); (B) Doxorubicin (from $1 \times 10^{-4}$ to $1 \times 10^{-7} \mathrm{M}$ ); (C) Paclitaxel (from 2.5 to $0.016 \mathrm{~nm}$ ) was tested. Mean \pm s.d. of growth percentage of treated vs untreated cells is reported.

Consistently with the preliminary biological indications derived from the most CHKA-comodulated genes, IPA functional analysis, identified as the most perturbed cellular functions those related to cell death and cellular proliferation and movement. The predicted alterations of these pathways were supposed to lead EOC cells towards a less tumourigenic behaviour.

Interestingly, LIMK1 was one of the genes downmodulated following CHKA silencing (see Table 1) and a reduced phosphorylation of the LIMK1/cofilin pathway at later time point after scratching was observed in CHKA-silenced cells (data not shown), suggesting that a long lasting dephosphorilation by impairing actin polimerisation might ultimately reduce cell migration (Mizuno, 2013). In this perspective, we indeed validated this prediction by showing a reduction of cell migration upon CHKA silencing. Furthermore, although we did not observe an increase in apoptosis, we could demonstrate in siCHKA cells an increased sensitivity to the main chemotherapeutic agent used for EOC treatment (platinum compounds) also in the highly platinum-resistant SKOV3 cell line. Importantly, we also observed a sensitisation of the CHKAsilenced cells to the other two drugs Paclitaxel and Doxorubicin that are currently in use in the clinical practice for EOC treatment in combination with platinum compounds. In agreement with the increased drug sensitivity, CCNA1 downmodulation following CHKA silencing might then impair the ability of cells to arrest cell cycle to repair DNA following DNA damage. Cyclin A1 is indeed a down-stream target of p53 able to mediate a G2/M cell-cycle arrest (Rivera et al, 2006). A cell sensitisation to drug treatment (5-fluoruracil) after CHKA silencing has been already reported also in the breast (Mori et al, 2007) and colorectal (de la Cueva et al, 2013) cancer cells.
When considering the biological relevance of CHKA knockdown it should be taken into account that the specific EOC molecular context may require longer time and a more persistent CHKA downregulation to achieve a more effective modulation of cell behaviour. A transient inhibition of CHKA in EOC could be not sufficient alone to maintain overtime the biological effect of its silencing. Indeed by a multidisciplinary approach, we showed that the alterations of the tCho MRS spectral profile observed in EOC cells is sustained also by the activation of other enzymes involved in PtdCho pathways such as PtdCho-plc (Iorio et al, 2005, 2010; Spadaro et al, 2008; Podo et al, 2011). It has also been shown that the decreased GPC to PCho ratio reported in several tumours could also be due to an increased cleavage of GPC to produce Cho by mean of the newly identified enzyme EDI3 (endometrial differential 3) (Stewart et al, 2012), which remain to be analysed in EOC. Then, both a CHKA stable inhibition as well as a simultaneous inhibition of the enzymes involved in both the biosynthetic as well as catabolic pathways could be more appropriated in these cellular models to obtain a stronger biological effect. Finally, the understanding of the possible different role of ChoK isoforms in carcinogenesis is at the moment a research great challenge (Gallego-Ortega et al, 2011; Gruber et al, 2012) that deserve to be further investigated in the next future.

In conclusion, the biological relevance of our results rests in the rescue to drug sensitivity of EOC cell lines when interfering with the Chok-alpha expression and activity. This supports the concept of targeting metabolism to improve efficacy of existing standard chemotherapeutic approaches (Vander Heiden, 2011) and opens the way to validate ChoK-alpha as a druggable target.

\section{ACKNOWLEDGEMENTS}

We thank Mrs Paola Alberti, Mrs Donata Penso, Mrs G Abolafio and Mr Edoardo Marchesi for their excellent technical support; Dr Maria Teresa Comito for her efforts in the initial setting of the experiments and Dr Zaver Bhujwalla for helpful discussion of our data. We also thank the NMR Joint facility (ISS, INFM, UniTV) at the Department of Chemistry of the University of Rome Tor Vergata for the good maintenance of the $16.4 \mathrm{~T}$ spectrometer. This study is supported by grants from the Italian Association for Cancer Research (IG-9147/2009 and 12976/2012 to DM).

\section{REFERENCES}

Agarwal R, Kaye SB (2003) Ovarian cancer: strategies for overcoming resistance to chemotherapy. Nat Rev Cancer 3: 502-516.

Aoki J, Inoue A, Okudaira S (2008) Two pathways for lysophosphatidic acid production. Biochim Biophys Acta 1781: 513-518.

Aoyama C, Liao H, Ishidate K (2004) Structure and function of choline kinase isoforms in mammalian cells. Prog Lipid Res 43: 266-281.

Bagnoli M, De Cecco L, Granata A, Nicoletti R, Marchesi E, Alberti P, Valeri B, Libra M, Barbareschi M, Raspagliesi F, Mezzanzanica D, Canevari S (2011) Identification of a chrXq27.3 microRNA cluster associated with early relapse in advanced stage ovarian cancer patients. Oncotarget 2: 1265-1278.

Banez-Coronel M, de Molina AR, Rodriguez-Gonzalez A, Sarmentero J, Ramos MA, Garcia-Cabezas MA, Garcia-Oroz L, Lacal JC (2008) Choline kinase alpha depletion selectively kills tumoral cells. Curr Cancer Drug Targets 8: 709-719.

Chon HS, Lancaster JM (2011) Microarray-based gene expression studies in ovarian cancer. Cancer Control 18: 8-15.

Chua BT, Gallego-Ortega D, Ramirez dM, Ullrich A, Lacal JC, Downward J (2009) Regulation of Akt(ser473) phosphorylation by Choline kinase in breast carcinoma cells. Mol Cancer 8: 131.

Clem BF, Clem AL, Yalcin A, Goswami U, Arumugam S, Telang S, Trent JO, Chesney J (2011) A novel small molecule antagonist of choline kinase-alpha 
that simultaneously suppresses MAPK and PI3K/AKT signaling. Oncogene 30: $3370-3380$.

de la Cueva A, Ramirez de Molina A, Varez-Ayerza N, Ramos MA, Cebrian A, Del Pulgar TG, Lacal JC (2013) Combined 5-FU and ChoKalpha inhibitors as a new alternative therapy of colorectal cancer: evidence in human tumor-derived cell lines and mouse xenografts. PLoS One 8: e64961.

Fang X, Yu S, Bast RC, Liu S, Xu HJ, Hu SX, LaPushin R, Claret FX, Aggarwal BB, $\mathrm{Lu}$ Y, Mills GB (2004) Mechanisms for lysophosphatidic acid-induced cytokine production in ovarian cancer cells. J Biol Chem 279: 9653-9661.

Gallego-Ortega D, Gomez del PT, Valdes-Mora F, Cebrian A, Lacal JC (2011) Involvement of human choline kinase alpha and beta in carcinogenesis: a different role in lipid metabolism and biological functions. Adv Enzyme Regul 51: 183-194.

Glunde K, Bhujwalla ZM, Ronen SM (2011a) Choline metabolism in malignant transformation. Nat Rev Cancer 11: 835-848.

Glunde K, Jiang L, Moestue SA, Gribbestad IS (2011b) MRS and MRSI guidance in molecular medicine: targeting and monitoring of choline and glucose metabolism in cancer. NMR Biomed 24: 673-690.

Glunde K, Raman V, Mori N, Bhujwalla ZM (2005) RNA interferencemediated choline kinase suppression in breast cancer cells induces differentiation and reduces proliferation. Cancer Res 65: 11034-11043.

Gruber J, See Too WC, Wong MT, Lavie A, McSorley T, Konrad M (2012) Balance of human choline kinase isoforms is critical for cell cycle regulation: implications for the development of choline kinase-targeted cancer therapy. FEBS J 279: 1915-1928.

Hanahan D, Weinberg RA (2011) Hallmarks of cancer: the next generation. Cell 144: 646-674.

Hernandez-Alcoceba R, Fernandez F, Lacal JC (1999) In vivo antitumor activity of choline kinase inhibitors: a novel target for anticancer drug discovery. Cancer Res 59: 3112-3118.

Iorio E, Di VM, Spadaro F, Ramoni C, Lococo E, Carnevale R, Lenti L, Strom R, Podo F (2003) Triacsin C inhibits the formation of $1 \mathrm{H}$ NMR-visible mobile lipids and lipid bodies in HuT 78 apoptotic cells. Biochim Biophys Acta 1634: 1-14.

Iorio E, Mezzanzanica D, Alberti P, Spadaro F, Ramoni C, D'Ascenzo S, Millimaggi D, Pavan A, Dolo V, Canevari S, Podo F (2005) Alterations of choline phospholipid metabolism in ovarian tumor progression. Cancer Res 65: 9369-9376.

Iorio E, Ricci A, Bagnoli M, Pisanu ME, Castellano G, Di Vito M, Venturini E, Glunde K, Bhujwalla ZM, Mezzanzanica D, Canevari S, Podo F (2010) Activation of phosphatidylcholine cycle enzymes in human epithelial ovarian cancer cells. Cancer Res 70: 2126-2135.

Iorio E, Ricci A, Pisanu ME, Bagnoli M, Podo F, Canevari S (2013) Choline metabolic profiling by magnetic resonance spectroscopy. Methods Mol Biol 1049: 255-270.

Ishidate K (1997) Choline/ethanolamine kinase from mammalian tissues. Biochim Biophys Acta 1348: 70-78.

Konstantinopoulos PA, Spentzos D, Cannistra SA (2008) Gene-expression profiling in epithelial ovarian cancer. Nat Clin Pract Oncol 5: 577-587.

Krishnamachary B, Glunde K, Wildes F, Mori N, Takagi T, Raman V, Bhujwalla ZM (2009) Noninvasive detection of lentiviral-mediated choline kinase targeting in a human breast cancer xenograft. Cancer Res 69: 3464-3471.

Kurman RJ, Shih I (2010) The origin and pathogenesis of epithelial ovarian cancer: a proposed unifying theory. Am J Surg Pathol 34: 433-443.

Mizuno K (2013) Signaling mechanisms and functional roles of cofilin phosphorylation and dephosphorylation. Cell Signal 25: 457-469.

Mori N, Gadiya M, Wildes F, Krishnamachary B, Glunde K, Bhujwalla ZM (2013) Characterization of choline kinase in human endothelial cells. NMR Biomed 26: 1501-1507.

Mori N, Glunde K, Takagi T, Raman V, Bhujwalla ZM (2007) Choline kinase down-regulation increases the effect of 5-fluorouracil in breast cancer cells. Cancer Res 67: 11284-11290.

Nilsson MB, Langley RR, Fidler IJ (2005) Interleukin-6, secreted by human ovarian carcinoma cells, is a potent proangiogenic cytokine. Cancer Res 65: 10794-10800.

Podo F (1999) Tumour phospholipid metabolism. NMR Biomed 12: 413-439.
Podo F, Canevari S, Canese R, Pisanu ME, Ricci A, Iorio E (2011) MR evaluation of response to targeted treatment in cancer cells. NMR Biomed 24: $648-672$.

Ramirez dM, Sarmentero-Estrada J, Belda-Iniesta C, Taron M, Ramirez dM V, Cejas P, Skrzypski M, Gallego-Ortega D, de Castro J, Casado E, Garcia-Cabezas MA, Sanchez JJ, Nistal M, Rosell R, Gonzalez-Baron M, Lacal JC (2007) Expression of choline kinase alpha to predict outcome in patients with early-stage non-small-cell lung cancer: a retrospective study. Lancet Oncol 8: 889-897.

Rivera A, Mavila A, Bayless KJ, Davis GE, Maxwell SA (2006) Cyclin A1 is a p53-induced gene that mediates apoptosis, G2/M arrest, and mitotic catastrophe in renal, ovarian, and lung carcinoma cells. Cell Mol Life Sci 63: 1425-1439.

Roberts RZ, Morris AJ (2000) Role of phosphatidic acid phosphatase 2a in uptake of extracellular lipid phosphate mediators. Biochim Biophys Acta 1487: $33-49$.

Rodriguez-Gonzalez A, Ramirez de MA, Banez-Coronel M, Megias D, Lacal JC (2005) Inhibition of choline kinase renders a highly selective cytotoxic effect in tumour cells through a mitochondrial independent mechanism. Int J Oncol 26: 999-1008.

Rodriguez-Gonzalez A, Ramirez de MA, Fernandez F, Ramos MA, del Carmen NM, Campos J, Lacal JC (2003) Inhibition of choline kinase as a specific cytotoxic strategy in oncogene-transformed cells. Oncogene 22: 8803-8812.

Sandercock J, Parmar MK, Torri V, Qian W (2002) First-line treatment for advanced ovarian cancer: paclitaxel, platinum and the evidence. Br J Cancer 87: 815-824.

Siegel R, Naishadham D, Jemal A (2013) Cancer statistics, 2013. CA Cancer J Clin 63: 11-30.

So J, Navari J, Wang FQ, Fishman DA (2004) Lysophosphatidic acid enhances epithelial ovarian carcinoma invasion through the increased expression of interleukin-8. Gynecol Oncol 95: 314-322.

Spadaro F, Ramoni C, Mezzanzanica D, Miotti S, Alberti P, Cecchetti S, Iorio E, Dolo V, Canevari S, Podo F (2008) Phosphatidylcholine-specific phospholipase $\mathrm{C}$ activation in epithelial ovarian cancer cells. Cancer Res 68: 6541-6549.

Stewart JD, Marchan R, Lesjak MS, Lambert J, Hergenroeder R, Ellis JK, Lau CH, Keun HC, Schmitz G, Schiller J, Eibisch M, Hedberg C, Waldmann H, Lausch E, Tanner B, Sehouli J, Sagemueller J, Staude H, Steiner E, Hengstler JG (2012) Choline-releasing glycerophosphodiesterase EDI3 drives tumor cell migration and metastasis. Proc Natl Acad Sci USA 109: $8155-8160$.

Vance JE, Vance DE (2004) Phospholipid biosynthesis in mammalian cells. Biochem Cell Biol 82: 113-128.

Vander Heiden MG (2011) Targeting cancer metabolism: a therapeutic window opens. Nat Rev Drug Discov 10: 671-684.

Vaughan S, Coward JI, Bast Jr RC, Berchuck A, Berek JS, Brenton JD, Coukos G, Crum CC, Drapkin R, Etemadmoghadam D, Friedlander M, Gabra H, Kaye SB, Lord CJ, Lengyel E, Levine DA, McNeish IA, Menon U, Mills GB, Nephew KP, Oza AM, Sood AK, Stronach EA, Walczak H, Bowtell DD, Balkwill FR (2011) Rethinking ovarian cancer: recommendations for improving outcomes. Nat Rev Cancer 11: 719-725.

Ward PS, Thompson CB (2012) Metabolic reprogramming: a cancer hallmark even warburg did not anticipate. Cancer Cell 21: 297-308.

Wu G, Aoyama C, Young SG, Vance DE (2008) Early embryonic lethality caused by disruption of the gene for choline kinase alpha, the first enzyme in phosphatidylcholine biosynthesis. J Biol Chem 283: 1456-1462.

Yalcin A, Clem B, Makoni S, Clem A, Nelson K, Thornburg J, Siow D, Lane AN, Brock SE, Goswami U, Eaton JW, Telang S, Chesney J (2010) Selective inhibition of choline kinase simultaneously attenuates MAPK and PI3K/AKT signaling. Oncogene 29: 139-149.

This work is published under the standard license to publish agreement. After 12 months the work will become freely available and the license terms will switch to a Creative Commons AttributionNonCommercial-Share Alike 3.0 Unported License.

Supplementary Information accompanies this paper on British Journal of Cancer website (http://www.nature.com/bjc) 